\title{
Neurotrophin-4 Is More Potent than Brain-Derived Neurotrophic Factor in Promoting, Attracting and Suppressing Geniculate Ganglion Neurite Outgrowth
}

\author{
Elizabeth M. Runge Natalia Hoshino Matthew J. Biehl Son Ton \\ M. William Rochlin
}

Biology Department, Loyola University Chicago, Chicago, III., USA

\section{Key Words \\ Axon - Guidance - Neurotrophin • Epithelium - Taste • \\ Development $\cdot$ p75}

\begin{abstract}
The geniculate ganglion, which provides innervation to taste buds in the anterior tongue and palate, is unique among sensory ganglia in that its neurons depend on both neurotrophin-4 (NT4) and brain-derived neurotrophic factor (BDNF) for survival. Whereas BDNF is additionally implicated in taste axon guidance at targeting stages, much less is known about the guidance role of NT4 during targeting, or about either neurotrophin during initial pathfinding. NT4 and BDNF have distinct expression patterns in vivo, raising the possibility of distinct roles. We characterized the influence of NT4 and BDNF on geniculate neurites in collagen I gels at early embryonic through postnatal stages. During early pathfinding to the tongue (embryonic days 12-13; E1213), NT4 and BDNF promote significantly longer outgrowth than during intralingual targeting (E15-18). NT4 is more potent than BDNF at stimulating neurite outgrowth and both factors exhibit concentration optima, i.e. intermediate concentrations $(0.25 \mathrm{ng} / \mathrm{ml} \mathrm{NT4}$ or $25 \mathrm{ng} / \mathrm{ml}$ BDNF) promote maximal neurite extension and high concentrations (10 ng/
\end{abstract}

ml NT4 or 200 ng/ml BDNF) suppress it. Only partial suppression was seen at E12 (when axons first emerge from the ganglion in vivo) and postnatally, but nearly complete suppression occurred from E13 to E18. We show that cell death is not responsible for suppression. Although blocking the p75 receptor reduces outgrowth at the optimum concentrations of NT4 and BDNF, it did not reduce suppression of outgrowth. We also report that NT4, like BDNF, can act as a chemoattractant for geniculate neurites, and that the tropic influence is strongest during intralingual targeting (E15-18). NT4 does not appear to act as an attractant in vivo, but it may prevent premature invasion of the epithelium by suppressing axon growth.

Copyright $\odot 2012$ S. Karger AG, Basel

\section{Introduction}

Brain-derived neurotrophic factor (BDNF) and neurotrophin-4 (NT4) exhibit the same affinity for their high-affinity receptor (TrkB) [1] and the same affinity for

E.M. Runge, N. Hoshino and M.J. Biehl made equivalent contributions to this work.

\section{KARGER \\ Fax +4161306 1234 \\ E-Mail karger@karger.ch}

www.karger.com
(C) 2012 S. Karger AG, Basel

0378-5866/12/0345-0389\$38.00/0

Accessible online at: www.karger.com/dne
Assoc. Prof. M. William Rochlin

Loyola University Chicago Biology Department, LSB 317B

1032 W. Sheridan Road, Chicago, IL 60660 (USA)

E-Mailwrochli@luc.edu 
their low-affinity receptor (p75) [2], but they have distinct distributions and functions during embryonic development $[3,4]$. Gustatory geniculate ganglion neurons, which innervate taste buds in fungiform and anterior foliate papillae in the tongue and taste buds throughout the palate, are unique among sensory neurons in that they depend on both BDNF and NT4, not only for survival [3, $5-7]$ but also for normal nerve development $[8,9]$. Therefore this system may be particularly advantageous for understanding the differences in how BDNF and NT4 are deployed during nervous system development. Our focus is on the role of these factors as guidance cues during taste nerve development.

Initial pathfinding of axons from the geniculate ganglion to the mouse tongue does not depend on either $\mathrm{BDNF}$ or NT4, as axons arrive in the tongue normally (albeit fewer in number) in the respective knockout mice [8]. However, both factors stimulate robust neurite extension in vitro at the equivalent stage (embryonic days 1213 , E12-13) in rats [10]. A dose-response analysis of the influence of NT4 or BDNF on neurite extension has not been carried out, nor is it known if either factor is sufficient to chemoattract E12-13 neurites. Once inside the presumptive tongue, geniculate axons decussate from the chorda tympani nerve (E14) and arborize beneath fungiform placode epithelium (targeting, E15-16 in rat) [1113]. mRNAs encoding BDNF and NT4 are expressed at their highest levels in the lingual epithelium and mesenchyme at the equivalent stage in mouse (E12.5-13.5) [14, 15]. In $B d n f-/-$ mice and in Ntf4/5-/- mice, axons decussate from the main branch of the chorda tympani in the ventral tongue and ascend through the mesenchyme toward dorsal epithelium, much as they do in wild-type mice [8]. However, in $B d n f / N t f 4 / 5$ double knockout mice, few fibers extend toward the dorsal lingual epithelium from the chorda tympani, suggesting that the combination of BDNF and NT4 supports geniculate axon growth within the mesenchyme. It is interesting that there is 4 -fold more Ntf4/5 mRNA than Bdnf in the epithelium, but 4-fold less Ntf4/5 mRNA than Bdnf in the mesenchyme at this stage [15], consistent with the possibility that these factors play distinct, location-specific roles depending on their concentrations.

Whereas the precise roles of NT4 and BDNF in early geniculate nerve development have not received much attention, several lines of evidence support a role for BDNF, but not NT4, in targeting, i.e. invasion of fungiform papilla epithelium that will differentiate into taste buds. Bdnf becomes concentrated in fungiform papilla epithelium just as axons exhibit targeting to this epithe- lium [16, 17], but $N t f 4 / 5$, which had been present at a 4-fold higher concentration than $B d n f$ at the onset of intralingual pathfinding, becomes nearly undetectable in the epithelium [15]. Geniculate axons in Bdnf-/- mice typically fail to invade target epithelium $[9,18]$, but axons target normally in Ntf4/5-/- mice [8]. Overexpressing $B d n f$ in the mesenchyme results in axons terminating in the mesenchyme [19]; and overexpressing Bdnf throughout the lingual epithelium causes axons to course along and branch extensively beneath the epithelium, and innervate filiform (nongustatory) papillae [20]. $\mathrm{BDNF}$ is sufficient to attract geniculate neurites in vitro at targeting/target invasion stages, further supporting its hypothesized role as a chemoattractant [21]. Intriguingly, overexpression of NT4 in the epithelium during targeting inhibits branching and exploration of the lingual epithelium [22], and our initial investigations suggested that NT4 stunts the growth of and does not attract geniculate neurites at targeting stages $[23,24]$. This raises the possibility that NT4 and BDNF differ fundamentally in their influences on geniculate axon growth during target selection. This view is supported by studies showing that a mutation in $\operatorname{trkB}$ that alters the cytosolic Shcbinding domain but not neurotrophin binding differentially affects NT4 and BDNF signaling [25]. However, our recent study revealed that BDNF has a concentration optimum for promoting outgrowth [21], suggesting an alternative interpretation - that differences in the influence of BDNF and NT4 on geniculate axons are due (in part) to NT4 having a greater potency than BDNF. NT4 has a higher potency than BDNF in promoting retinal ganglion cell neurite outgrowth [26] and dopamine uptake by ventral mesencephalic neurons [27]. Also, when $N t f 4 / 5$ is knocked into the $B d n f$ gene locus, it not only rescues the geniculate ganglion neurons that would have been lost in $B d n f-/-$ mice, but is a more potent survival factor than BDNF (based on gene dosage) [28]. NT4 is also more potent than BDNF in supporting synapse formation in hippocampal cultures in vitro [28]. Thus, it is imperative to compare the potencies of NT4 and BDNF as trophic and tropic factors for geniculate neurites at targeting stages.

TrkB expression remains fairly constant in the mouse geniculate ganglion from E12.5 through birth [15], and BDNF continues to be expressed throughout life in the subset of the taste cells that form classical synapses with afferents [29]. Given that taste cells undergo turnover throughout life [30] and that regeneration of severed geniculate axons occurs with specificity [31, 32], BDNF could continue to act as an attractant. However, we found 
that while BDNF continued to exert a significant trophic (growth-promoting) effect on postnatal geniculate neurites, a tropic (attractive) influence was no longer apparent [21]. We therefore determined if the response to NT4 changed similarly to that of BDNF postnatally.

\section{Materials and Methods}

The procedures for culturing explants in collagen I gels, preparing beads, labeling, imaging, and assessing outgrowth are identical to those described in [21] except that either NT4 (Sigma) or BDNF (Prospec) was used and embryos from E12-13 rats were also used. Unless indicated otherwise, the culture duration was 2 days. At least 2 experiments were conducted for every data point presented except when we tested extremely high concentrations of neurotrophins (50 and $200 \mathrm{ng} / \mathrm{ml} \mathrm{NT4}$, and $1 \mu \mathrm{g} / \mathrm{ml} \mathrm{BDNF}$ ) on E12 explants.

To evaluate cell death in ganglia, we used a propidium iodide exclusion assay [33]. Cultures were washed with PBS twice at $46 \mathrm{~h}$, and then incubated with PBS containing $20 \mu \mathrm{g} / \mathrm{ml}$ propidium iodide for $5 \mathrm{~min}$ at $37^{\circ} \mathrm{C}$. The cultures were then washed with PBS twice, the original medium was replaced and they were placed back in the $5 \% \mathrm{CO}_{2}$ incubator until fixation $(\sim 15$ min later). After fixation, these cultures were labeled with $2 \mathrm{H} 3$ followed by donkey anti-mouse Dylight 649 (Jackson Laboratories). Propidium iodide was imaged using the settings for Alexafluor 568 . Z-stack projections were prepared and we set a threshold of $60 \%$ of the maximum fluorescence to eliminate background fluorescence. By counting profiles in the $z$-stack projection rather than individual optical sections, we avoided the problem of double counting labeled nuclei. This method leads to an underestimate of the total number of labeled nuclei since nuclei positioned in the same $\mathrm{x}, \mathrm{y}$ position but different $\mathrm{z}$ position would be counted as only one nucleus. The resulting underestimation error is expected to be greater when the density of labeled nuclei is higher, which provides a conservative method for detecting different levels of cell death. ANOVA was used to compare the values across treatments.

To test the role of p75, we used REX, a function-blocking rabbit polyclonal antibody developed against rat p75 (generously provided by Dr. L. Reichardt) [34]. REX serum or normal rabbit serum (control) was used at a 1:50 dilution. This would yield approximately $20 \mu \mathrm{g} / \mathrm{ml}$ anti-p75 IgG, which has been shown to be sufficient to block p 75 function in vitro [35]. After $24 \mathrm{~h}$, we supplemented the cultures with $25 \%$ of the initial amount of REX or rabbit serum to ensure continued maintenance of the p75 inhibition.

For 2-ganglion tropism assays (see 'Results'), we compared proximal growth toward the bead from the distant ganglion ('prox. far') to distal outgrowth from the ganglion near the bead ('dist. near') using Student's t test for pairwise comparisons and a cut-off of $\mathrm{p}<0.05$. We only considered ganglion pairs if there was non-zero outgrowth from the proximal or distal quadrants of both ganglia (i.e. if either ganglion exhibited no growth or growth only in the other two quadrants, the pair was not used in the analysis). We also excluded cases in which the proximal and distal outgrowth intermingled extensively and could not be distinguished. Owing to the variable outgrowth among cultures and the need to fix cultures prior to intermingling of proximal and distal neurites or contact of the closer ganglion by proximal neurites of the distant ganglion, cultures were monitored periodically and fixed between 18 and $38 \mathrm{~h}$ after plating.

\section{Results}

NT4 and BDNF Stimulate Neurite Outgrowth from E12 through Postnatal Stages: The Effects Are Stage Dependent and There Is a Concentration Optimum

Geniculate ganglia were dissected at five stages of development: E12, when the first axons are exiting the ganglion to form the initial segments of peripheral nerves; E13, when axons are arriving in the lingual swellings that will give rise to the tongue $[10,12]$; E15, when axons are arborizing within the tongue and lining up beneath the fungiform papilla epithelium; E18 when axons have just entered the target epithelium [11], and during the first postnatal week (PN) as taste pores are opening [36]. In the absence of added neurotrophic factors, embryonic geniculate ganglion explants appeared to disintegrate and few if any neurites were observed (fig. 1b-d, inset), as shown previously for E12-18 ganglia [10, 21]. In contrast, PN ganglion explants exhibited neurotrophin-independent outgrowth in collagen gels after 2 days (fig. 1e, inset, from Hoshino et al. [21]). Exogenous NT4 and BDNF stimulated neurite outgrowth at all stages, as discussed below.

At E12, $0.0625 \mathrm{ng} / \mathrm{ml} \mathrm{NT4}$ stimulated a small amount of neurite outgrowth, and robust outgrowth was observed at a range of concentrations: $0.25,1,2.5$ and $10 \mathrm{ng} /$ $\mathrm{ml}$ (fig. 1a, 2a). In contrast, the effects of NT4 on neurite outgrowth from E13 ganglia varied significantly over this range and indicated a concentration optimum. The outgrowth increased from 0.0625 to $0.25 \mathrm{ng} / \mathrm{ml}$, then decreased significantly at $1 \mathrm{ng} / \mathrm{ml}$, again at $2.5 \mathrm{ng} / \mathrm{ml}$, and again to virtually no outgrowth at $10 \mathrm{ng} / \mathrm{ml}$ (fig. $1 \mathrm{~b}, 2 \mathrm{a}$ ). A few lengthy neurites were extended from the explants treated with $10 \mathrm{ng} / \mathrm{ml} \mathrm{NT4}$ (fig. 1b, arrowheads), perhaps derived from the most recently born neurons. In light of the suppression of outgrowth observed at E13, we tried higher concentrations of NT4 (50 and $200 \mathrm{ng} / \mathrm{ml}$ ) at E12. These treatments reduced outgrowth by about $50 \%$, a far less dramatic effect than $10 \mathrm{ng} / \mathrm{ml} \mathrm{NT4}$ at E13. This indicates that there is an optimum concentration range of NT4 for promoting neurite outgrowth at E12 but with different kinetics than observed at E13 and later stages (see below).

E15 (fig. 1c) and E18 (fig. 1d) ganglia exhibited dose responses similar to those at E13 for concentrations rang- 

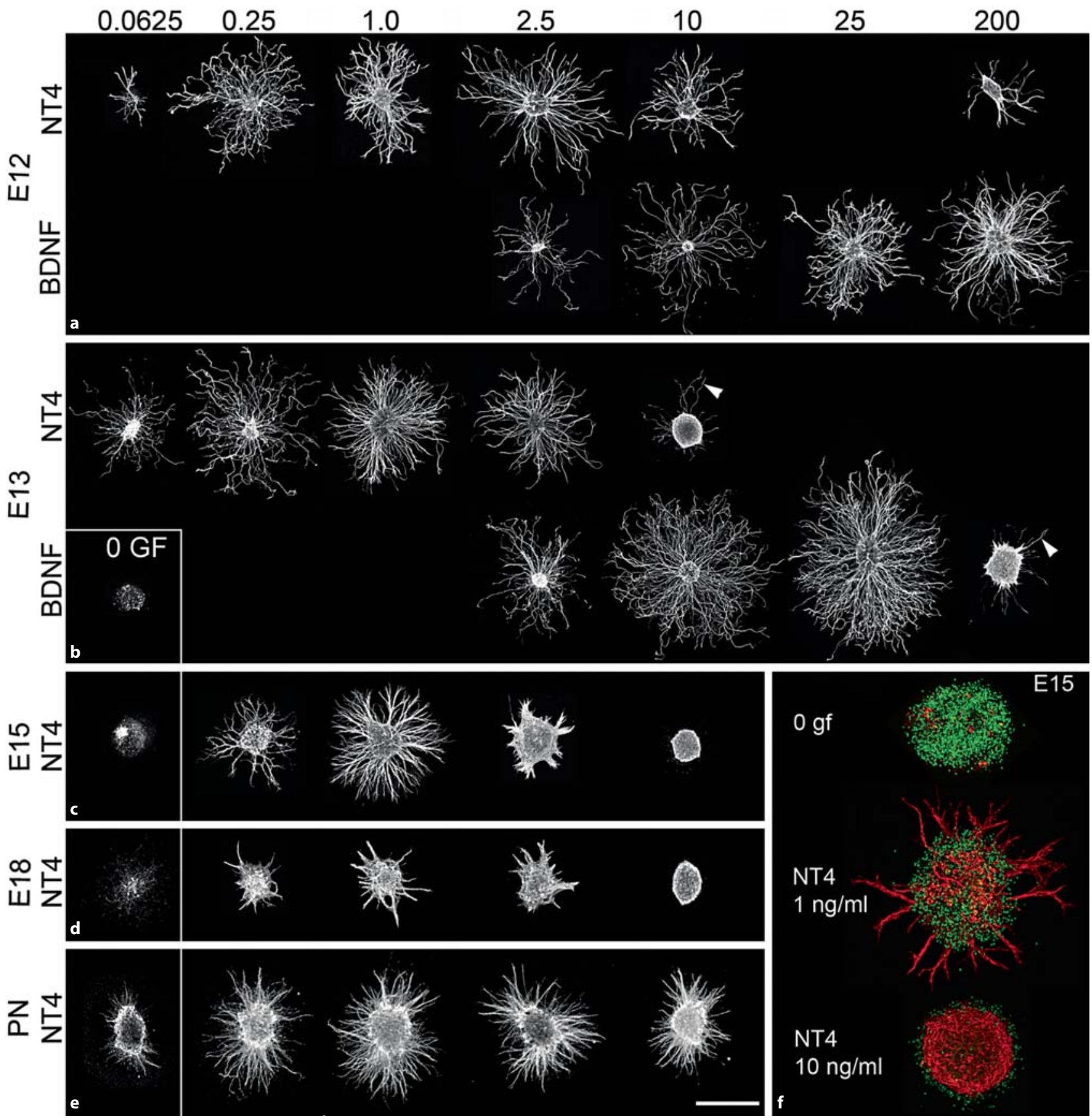

Fig. 1. NT4 is more potent than BDNF at stimulating and suppressing geniculate neurite outgrowth in collagen I gels. Ganglia were dissected from E12 (a), E13 (b), E15 (c), E18 (d), and postnatal ( $<1$ week) rats $(\mathbf{e})$. The longest neurites were observed at $0.25-$ $1 \mathrm{ng} / \mathrm{ml} \mathrm{NT} 4$ or $25 \mathrm{ng} / \mathrm{ml}$ BDNF. E12 was the only stage at which high concentrations of NT4 $(10 \mathrm{ng} / \mathrm{ml})$ or BDNF $(200 \mathrm{ng} / \mathrm{ml}) \mathrm{did}$ not suppress or reduce neurite growth, although at E13 a few lengthy neurites were consistently observed (arrowheads). Partial suppression of outgrowth from E12 ganglia was observed at 200 $\mathrm{ng} / \mathrm{ml} \mathrm{NT4}$. NT4 and BDNF elicited more growth at E12-13 than at later embryonic stages (cf. [21]). At embryonic stages, no outgrowth was observed in the absence of growth factor ( 0 gf; shown for E13-18 (b-d, inset), cf. [10, 21]). A small amount of neurite outgrowth was observed from postnatal ganglia in the absence of exogenous neurotrophins (e, inset). f Red staining is $2 \mathrm{H} 3$ (neurites), green staining is propidium iodide. To determine if the $a b$ sence of outgrowth at high neurotrophin concentrations was due to cell death, we conducted propidium iodide exclusion assays using E15 geniculate ganglia. Extensive cell death was observed in the absence of neurotrophin, moderate cell death was observed at an optimum concentration of NT4 for outgrowth $(1 \mathrm{ng} / \mathrm{ml})$, and little cell death was observed at a concentration of NT4 that suppresses outgrowth $(10 \mathrm{ng} / \mathrm{ml})$. Calibration bar in $\mathbf{e}=500 \mu \mathrm{m}$ for a-e and $200 \mu \mathrm{m}$ for $\mathbf{f}$. 
ing from 0.25 to $10 \mathrm{ng} / \mathrm{ml}$, but the radius of the outgrowth halo was less than half of that observed at E12/13. In addition, the dose responses at E15 and E18 were shifted slightly to the right compared to E12/13 ganglia; whereas the optimum at E12/13 was observed at $0.25 \mathrm{ng} / \mathrm{ml} \mathrm{NT4}$, the optimum at E15/18 was $\sim 1 \mathrm{ng} / \mathrm{ml} \mathrm{NT4}$. Also, 0.0625 $\mathrm{ng} / \mathrm{ml}$ promoted notable outgrowth at E13, but E15 geniculate ganglia disintegrated without emitting neurites when $0.0625 \mathrm{ng} / \mathrm{ml} \mathrm{NT4}$ was used ( $\mathrm{n}=5$, not shown). At E18, we observed a lower density of outgrowth compared to all other stages. For PN ganglia (fig. 1e), 0.25, 1, and 50 $\mathrm{ng} / \mathrm{ml}$ NT4 stimulated significantly more outgrowth than no added neurotrophin. Higher concentrations $(2.5-50 \mathrm{ng} / \mathrm{ml}) \mathrm{had}$ less of a suppressive influence at this stage. Pairwise comparisons between each of these higher concentrations and either of the apparent optimal concentrations $(0.25$ and $1 \mathrm{ng} / \mathrm{ml})$ did not result in significant differences (fig. 2a). However, the pooled outgrowth from $2.5,10$ and $50 \mathrm{ng} / \mathrm{ml} \mathrm{NT} 4$ was significantly less than the 0.25 and $1 \mathrm{ng} / \mathrm{ml} \mathrm{NT4}$ treatments, indicating that there is still an NT4 optimum at the postnatal stage.

Dose response results with BDNF were analogous to those for NT4, but 40-100 times higher concentrations of BDNF were needed to stimulate robust outgrowth (fig. 1, 2b). As with NT4, using an extremely high dose of BDNF $(1 \mu \mathrm{g} / \mathrm{ml})$ was needed to obtain a partial suppression of outgrowth at E12 (fig. 2b). At E13, 20-fold more BDNF was needed to suppress outgrowth to the extent observed with $10 \mathrm{ng} / \mathrm{ml} \mathrm{NT4}$, but at E15 and E18 even $1 \mu \mathrm{g} / \mathrm{ml}$ BDNF (data not shown) did not suppress outgrowth as completely as $10 \mathrm{ng} / \mathrm{ml} \mathrm{NT4}$. Note that the BDNF data for E15 through postnatal stages for concentrations up to 200 $\mathrm{ng} / \mathrm{ml}$ were published previously [21].

The suppression of outgrowth by NT4 could be due to death of the neurons. This is unlikely given that the morphology of the ganglion explants treated with $10 \mathrm{ng} / \mathrm{ml}$ NT4 is similar to that of ganglia treated with the optimal concentration of NT4, whereas ganglia treated with no growth factor disintegrate. Furthermore, neurites can be seen coursing throughout explants treated with $10 \mathrm{ng} / \mathrm{ml}$ NT4. Nonetheless, we evaluated cell death in E15 geniculate ganglion explants using a propidium iodide exclusion assay. This dye rapidly enters dead cells and intercalates into their DNA. As shown in figure 1f, the number of propidium iodide-stained nuclei is much greater in explants cultured without exogenous neurotrophins $(762.4 \pm 118.2 \mathrm{SD})$ than in those treated with $1 \mathrm{ng} / \mathrm{ml}$ $(226.3 \pm 56.3)$ or $10 \mathrm{ng} / \mathrm{ml} \mathrm{NT4}(97.3 \pm 66.2)$. All differences were significant by ANOVA using a Bonferroni post hoc test. Surprisingly, significantly less cell death occurs in $10 \mathrm{ng} / \mathrm{ml}$ NT4-treated cultures than in those treated with $1 \mathrm{ng} / \mathrm{ml} \mathrm{NT4}$, which is optimal for neurite outgrowth. These data imply that cell death is not responsible for the suppression of neurite outgrowth by 10 $\mathrm{ng} / \mathrm{ml} \mathrm{NT4}$.

To determine if p75 is required for outgrowth or suppression of outgrowth at high neurotrophin concentrations, we treated cultures with $2 \%$ nonimmune rabbit serum (control) or $2 \%$ neutralizing rabbit anti-p75 serum. Neurite outgrowth length in the presence of optimum concentrations of NT4 or BDNF was decreased by antip75 at all embryonic stages, but the effect was most dramatic at E15 (fig. 2c; online supplementary fig. 1; see www. karger.com/doi/10.1159/000342996). Thus, p75 is necessary for neurite growth rates observed at optimal concentrations of NT4 and BDNF. Since blocking p75 significantly reduced neurite outgrowth regardless of the neurotrophin being used to stimulate outgrowth, this implies that p75 activation occurs despite a 25 - to 50 -fold difference in the concentrations of NT4 and BDNF. When E15 geniculate explants were treated with concentrations of neurotrophins that suppressed neurite outgrowth (10 ng/ $\mathrm{ml} \mathrm{NT4}$ or $200 \mathrm{ng} / \mathrm{ml}$ BDNF), anti-p75 treatment did not reduce the suppression of neurite outgrowth (fig. $2 c$; online suppl. fig. 1I, J), arguing against a role for p75 in the suppression of neurite extension. Note that anti-p75 was sufficient to significantly reduce the small amount of outgrowth observed when $200 \mathrm{ng} / \mathrm{ml} \mathrm{BDNF}$ was used to suppress outgrowth at E15 (fig. 2c).

\section{Gradients of NT4 and BDNF Bias Neurite Outgrowth}

To determine if NT4 and BDNF exert a tropic effect on geniculate neurites, ganglia were cocultured with Affigel blue beads that had been soaked in $0.5 \mathrm{mg} / \mathrm{ml} \mathrm{BSA}$ in PBS (control) or a neurotrophin in $0.5 \mathrm{mg} / \mathrm{ml} \mathrm{BSA}$. Neurite outgrowth was not biased by the control beads at any stage (fig. 3a, fig. 4a-d, images for stages other than E15 are available upon request from the corresponding author). For quantification and statistical analysis we measured the radius of the halo of outgrowth toward the bead and away from the bead (see 'Methods') and took their ratio. The absence of distal outgrowth at targeting stages prevented us from determining the proximal to distal outgrowth ratio, so we instead used the ratio of distal to proximal neurite growth (fig. 4d). Using this ratio, lower values evidence greater attraction bias. In our previous study we used beads soaked in $5 \mu \mathrm{g} / \mathrm{ml}$ BDNF [21]. We found that beads prepared in $5 \mu \mathrm{g} / \mathrm{ml}$ NT4 promoted little growth and that this growth was undirected [23]. We therefore soaked beads in two lower concentrations of 
NT4 $(0.5$ and $1.25 \mu \mathrm{g} / \mathrm{ml})$ and also tried two concentrations of BDNF (1.25 or $5 \mu \mathrm{g} / \mathrm{ml})$. At E12, beads soaked in either concentration of NT4 or the low concentration of BDNF significantly biased neurite outgrowth (fig. 4a, d) but the bias was small. In part this may have been due to the greater variability in neurite outgrowth at this stage. Similar results were obtained at E13 (fig. 4b, d). To verify that the effect of NT4 was saturable (as was shown previously for BDNF), we added $0.5 \mathrm{ng} / \mathrm{ml} \mathrm{NT} 4$ to the bath for E13 geniculate ganglia cocultured with $0.5 \mu \mathrm{g} / \mathrm{ml} \mathrm{NT4}$ beads. The bias was not significantly different from that observed with control beads (fig. 4b, d).

At E15 (targeting), geniculate neurites grew nearly exclusively toward the NT4 beads (fig. 3b; 4c, d): only 2 of

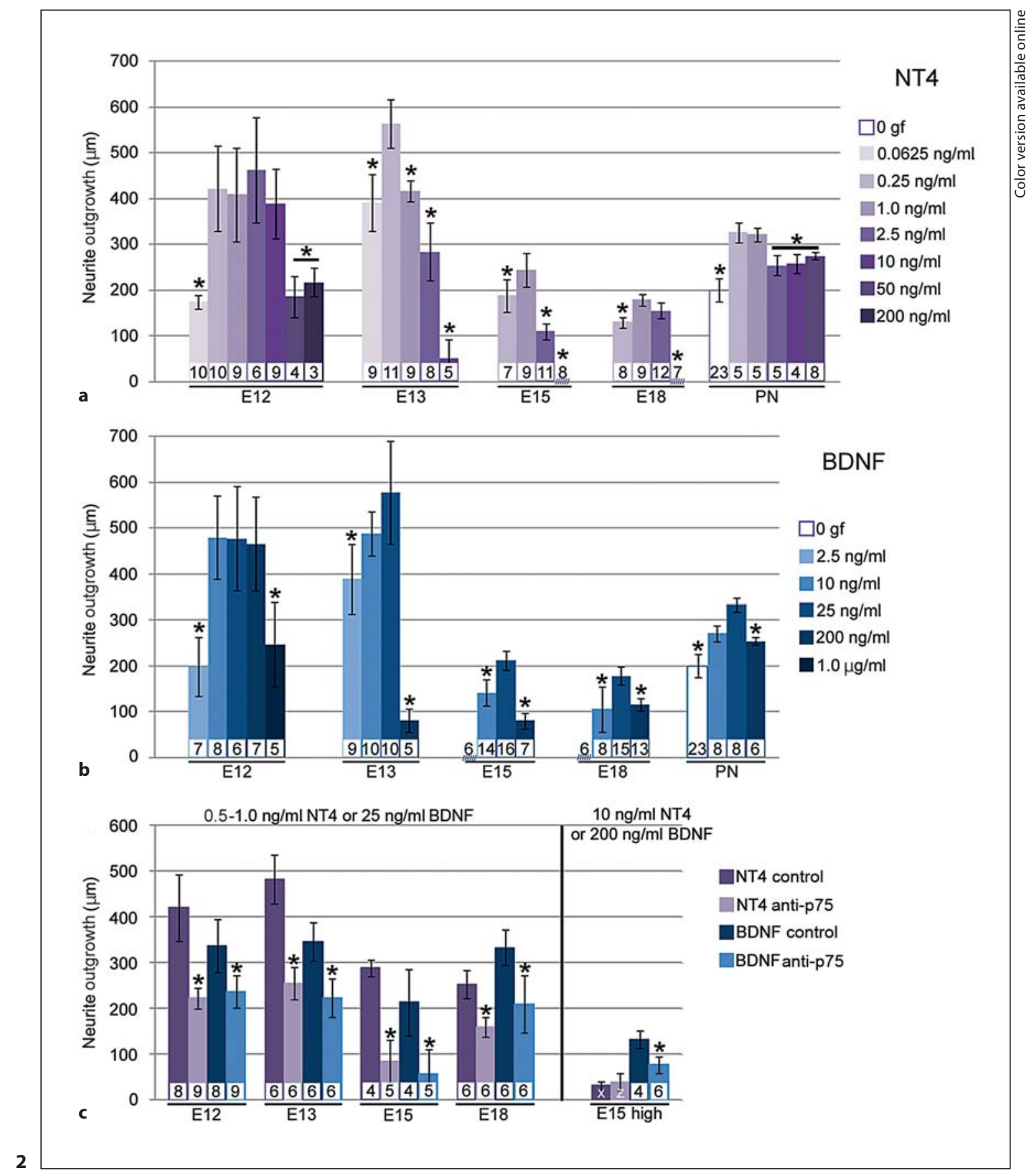


20 ganglia exhibited distal outgrowth at this stage when using the $0.5 \mu \mathrm{g} / \mathrm{ml} \mathrm{NT4-treated} \mathrm{beads,} \mathrm{and} 2$ of 6 had distal growth using the $1.25 \mu \mathrm{g} / \mathrm{ml}$ NT4 beads. At E18 (just after target penetration), the bias in neurite outgrowth was highly significant as well (fig. 4c, d), particularly when the high concentration $(1.25 \mu \mathrm{g} / \mathrm{ml})$ NT4 beads were used. Our previously published results with $5 \mu \mathrm{g} / \mathrm{ml} \mathrm{BDNF}$ beads were nearly identical to results using NT4 beads for E15 and E18 ganglia: at E15, only 4 out of 19 ganglia exhibited distal outgrowth, and the bias ratios were comparably low at both stages [21]. The distal:proximal ratios obtained with control and BDNF beads are shown in figure $4 \mathrm{~d}$. Thus, at targeting and target penetration stages, neurite outgrowth is strongly biased by gradients of either NT4 or BDNF. PN ganglia also exhibited significantly lower distal to proximal outgrowth ratios in the presence of $0.5 \mu \mathrm{g} / \mathrm{ml} \mathrm{NT4}$ beads than in the presence of control beads (fig. 4c, d). BDNF beads, however, did not elicit a bias in neurite outgrowth from postnatal ganglia [21].

To determine if bias ratios differed significantly over the course of development, we compared average bias ratios using ANOVA in combination with a Tukey post hoc adjustment. For NT4, we used ratios obtained with beads that were prepared with the lower concentration (light purple-striped bars, fig. $4 \mathrm{~d}$ ) for all but the E18 stage (dark purple-striped bar, fig. 4d). For BDNF, we used ratios obtained with beads prepared from the low concentration

Fig. 2. Quantification of neurite outgrowth stimulated by bath applied NT4 or BDNF, and in anti-p75 experiments. Error bars represent twice the SEM, which provides an indication of which differences are significant [56] based on pairwise comparisons. Significance was assessed as described previously [21]. For a and b, asterisks indicate which bars were significantly different from the optimal outgrowth at that stage with that neurotrophin. Other significant differences are mentioned below and in 'Results'. a NT4: At E12, $0.0625 \mathrm{ng} / \mathrm{ml} \mathrm{NT4}$ was significantly different from the outgrowth at concentrations from $0.25 \mathrm{ng} / \mathrm{ml}$ to $10 \mathrm{ng} / \mathrm{ml}$, as were the pooled 50 and $200 \mathrm{ng} / \mathrm{ml}$ treatments. At E13, outgrowth at each concentration differed significantly from outgrowth at all other concentrations except that outgrowth at $0.0625 \mathrm{ng} / \mathrm{ml} \mathrm{did}$ not differ significantly from outgrowth at $1.0 \mathrm{ng} / \mathrm{ml}$. At E15, all values differed significantly from one another. At E18, outgrowth at $0.25 \mathrm{ng} / \mathrm{ml}$ differed significantly from outgrowth at $1.0 \mathrm{ng} / \mathrm{ml}$, and outgrowth at $10 \mathrm{ng} / \mathrm{ml}$ differed significantly from all others, but no other differences reached significance. At PN, outgrowth with no growth factor ( 0 gf) differed significantly from outgrowth at $0.25,1.0$ and $50 \mathrm{ng} / \mathrm{ml}$, but there were no other significant pairwise differences. The pooled results from 2.5, 10 and 50 for E12 and E13 (light blue-striped bars, fig. 4d), and from the high concentration for E15, E18, and postnatal stages (dark blue striped bars, fig. $4 \mathrm{~d}$ ). We pooled the ratios of the E12 and E13 beads for both NT4 and BDNF (none of which differed significantly from one another), and the ratios of the E15 and E18 beads (only one of which differed significantly from the others; the E18 BDNF ratio was significantly higher than the other three ratios). The pooled E15/E18 ratio was significantly lower than the pooled E12/E13 ratio and the individual postnatal NT4 and BDNF ratios. Pairwise comparisons between E15 and E18 ratios from either NT4 or BDNF beads were also significantly lower than E12, E13, and PN ratios with the following exceptions: the E18 BDNF bead ratio was not significantly different from E13 NT4 or BDNF bead ratios or the PN NT4 bead ratio. Thus, when targeting occurs, geniculate neurites are maximally sensitive to the biasing influence of NT4 and BDNF.

To help distinguish between a purely trophic (growth promoting) effect and a tropic (guidance) effect, we tested if neurites extend more rapidly toward the neurotrophin bead than away from the bead when they are experiencing the same amount of neurotrophin. To this end, we used a '2-ganglion' paradigm in which two ganglia were placed in series on one side of the bead [37]. This affords certainty that the neurotrophin concentration experienced by the distant ganglion is less than or equal to that of the closer ganglion. If the proximal neurites of the $\mathrm{ng} / \mathrm{ml}$ NT4 were significantly different from 0.25 and $1.0 \mathrm{ng} / \mathrm{ml}$ NT4. b BDNF: At E12, the only significant differences in outgrowth were between outgrowth at $2.5 \mathrm{ng} / \mathrm{ml}$ and that at $10 \mathrm{ng} /$ $\mathrm{ml}$, and those between $1 \mu \mathrm{g} / \mathrm{ml}$ and 10, 25, and $200 \mathrm{ng} / \mathrm{ml}$. At E13, outgrowth at $2.5 \mathrm{ng} / \mathrm{ml}$ differed significantly from that at $25 \mathrm{ng} /$ $\mathrm{ml}$, and outgrowth at $200 \mathrm{ng} / \mathrm{ml}$ differed significantly from all others. At E15 and E18, outgrowth at $25 \mathrm{ng} / \mathrm{ml}$ differed significantly from all others. At PN, outgrowth at $25 \mathrm{ng} / \mathrm{ml}$ differed significantly from that with 0 gf and $200 \mathrm{ng} / \mathrm{ml}$. In cases in which there is no bar, no outgrowth was observed (NT4, $10 \mathrm{ng} / \mathrm{ml}, \mathrm{E} 15$ and E18). c When optimal concentrations of neurotrophin were used to promote outgrowth (left 3/4ths of the graph), anti-p75 (lighter bar of each pair) reduced neurite outgrowth significantly (asterisks) compared to control rabbit serum-treated ganglia (darker bar of each pair). The inhibition effect was most dramatic at E15. When concentrations of neurotrophins that suppress outgrowth $(10 \mathrm{ng} / \mathrm{ml} \mathrm{NT4}$ or $200 \mathrm{ng} / \mathrm{ml} \mathrm{BDNF})$ were used (E15 high), suppression was not reduced by anti-p75 treatment. Antip75 significantly reduced the small amount of outgrowth observed at E15 when BDNF was used. The white ' $x$ ' and ' $z$ ' in 'E15 high' NT4 bars correspond to n values of 4 and 6, respectively. 
more distant ganglion are the same length as the distal neurites of the closer ganglion, then neurite growth rate is attributable to the amount of neurotrophin experienced, and it is not influenced by the direction of the gradient, i.e. the neurotrophin is essentially trophic. If proximal neurites from the distant ganglion are longer than distal neurites of the closer ganglion, then neurites grow faster toward the source of neurotrophin than away from it, an indication that the neurotrophin exerts a tropic effect. We used beads that had been soaked in either the high or the low concentration of NT4 and BDNF for these assays, but typically one concentration was more effective than the other in eliciting outgrowth that met the criterion, and this depended on the stage (low concentration beads were more effective at E12-13; high concentration beads at E15/18).
Fig. 3. Gradients of NT4 or BDNF bias neurite outgrowth from E15 geniculate ganglia and the effect is tropic. Control (cntl) beads (a) did not bias outgrowth, but NT4 beads (bd) strongly biased outgrowth (b). In two ganglion tropism assays, NT4 beads (c) rarely promoted growth from the distant ganglion (10 of 30 pairs), but in these cases there was no distal growth from the proximal ganglion. BDNF beads (d) also produced significantly longer growth toward the bead from the distal ganglion than distal growth from the proximal ganglion. Calibration bar $=250$ $\mu \mathrm{m}$.
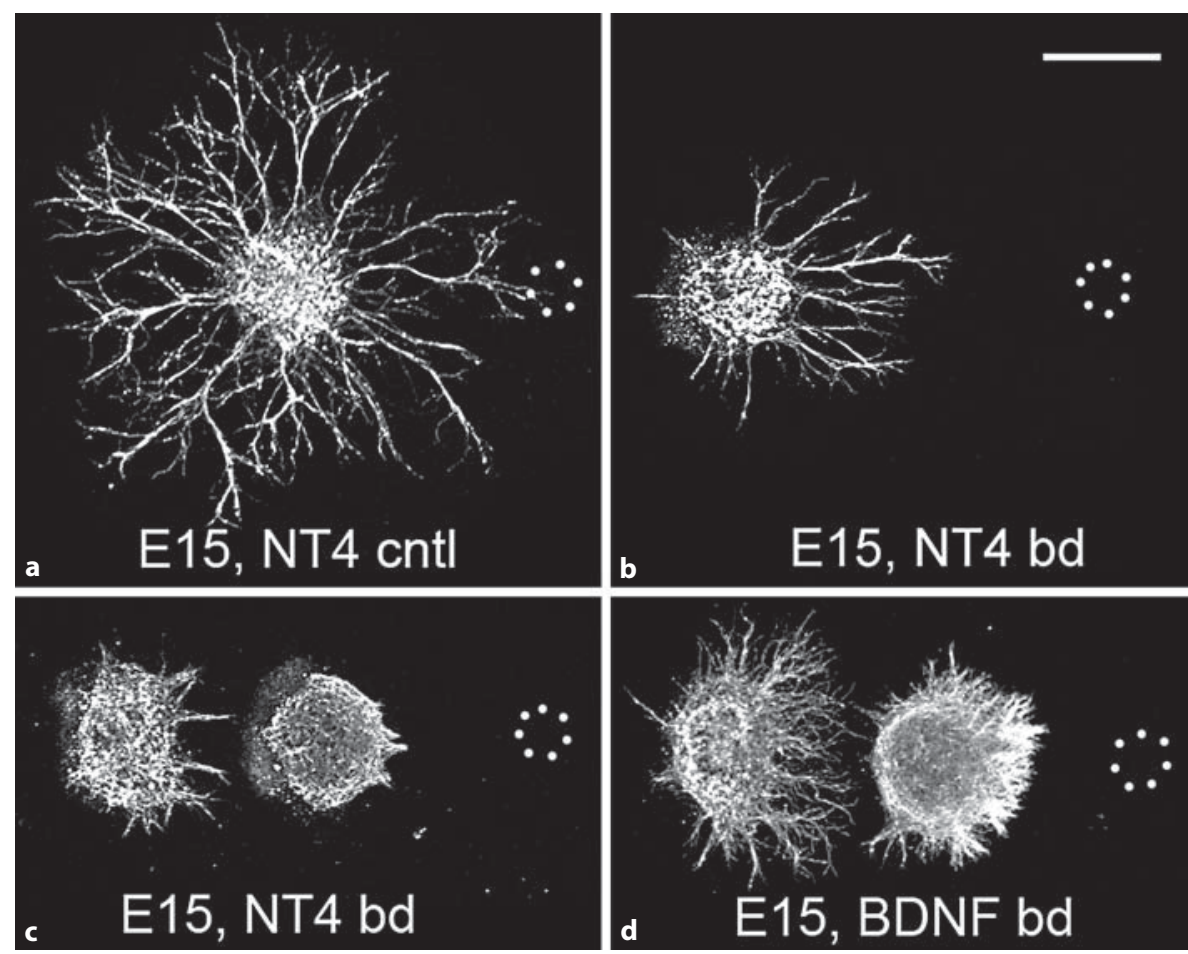

Fig. 4. Quantitation of neurite outgrowth (a-c) and neurite outgrowth bias ratios (d) in bead/ganglion cocultures. The concentration of growth factor ([GF]) in $\mu \mathrm{g} / \mathrm{ml}$ in which beads were soaked prior to culture is given below the $\mathrm{x}$-axis. For control beads $([\mathrm{GF}]=0)$, outgrowth was promoted by bath application of $0.5 \mathrm{ng} /$ $\mathrm{ml} \mathrm{NT4}$ or $25 \mathrm{ng} / \mathrm{ml} \mathrm{BDNF}$ for embryonic cultures, or $50 \mathrm{ng} / \mathrm{ml}$ NT4 or BDNF for postnatal cultures. a-c Average proximal outgrowth (toward the bead) after $48-50 \mathrm{~h}$ in vitro (except E12, 40$42 \mathrm{~h}$ in vitro) is indicated by the left bar of each pair, average distal outgrowth is indicated by the right bar. For 2-ganglion assays ('2GG'), 'Prox Far' refers to growth toward the bead from the distant ganglion; 'Dist Near' refers to growth away from the bead by the closer ganglion. Asterisks indicate significant differences $(\mathrm{p}<$ 0.05, see 'Methods'). a For the 2-ganglion study at E12, the 'Prox Far' and 'Dist Near' difference was significant for BDNF beads but not for NT4 beads. b In 2-ganglion assays at E13, 'Prox Far' growth was significantly longer than 'Dist Near' growth for both NT4 and
BDNF beads. c At E15, geniculate outgrowth is strongly biased by NT4 beads, i.e. there was no distal outgrowth from any of the 7 closer ganglia. 'Prox Far' growth is significantly greater than 'Dist Near' growth for both NT4 and BDNF beads. At E18, 'Prox Far' growth was also significantly longer than 'Dist Near' growth. Postnatal (PN) geniculate neurite outgrowth was greater toward the NT4 beads, but distal growth was too long to make 2-ganglion studies feasible. $\mathbf{d}$ The ratio of the distal neurite growth to proximal neurite growth was calculated for each ganglion and averaged for each condition. At every stage, neurite outgrowth is significantly biased (asterisks) by NT4 (purple) and BDNF beads (blue), but the amount of bias depends on the stage and the amount of neurotrophic factor in which the beads had been soaked. Adding $0.5 \mathrm{ng} / \mathrm{ml} \mathrm{NT} 4$ to the bath eliminated the bias caused by $0.5 \mu \mathrm{g} / \mathrm{ml}$ NT4 beads (third bar from left at E13). Bar legend: White bars correspond to distal:proximal outgrowth ratios using control beads. All other bars correspond to NT4 or BDNF beads. 
Using E12 geniculate ganglia, the 2-ganglion assay did not support a predominantly tropic role for NT4 (fig. 4a, images for stages other than E15 are available upon request from the corresponding author), although there was a trend toward greater proximal outgrowth than distal outgrowth. Outgrowth at this stage was highly variable both in length and uniformity around the perimeter of the explant, preventing the difference between proximal growth from the distant ganglion and distal growth from the closer ganglion from reaching significance. BDNF beads, however, did elicit significantly longer proximal outgrowth than distal outgrowth (fig. 4a). At E13, proximal outgrowth of the distant ganglion was significantly longer than distal outgrowth from the near ganglion for both NT4 and BDNF beads (fig. 4b). This indicates that, at least for NT4, the tropic influence is greater at E13 than at E12.

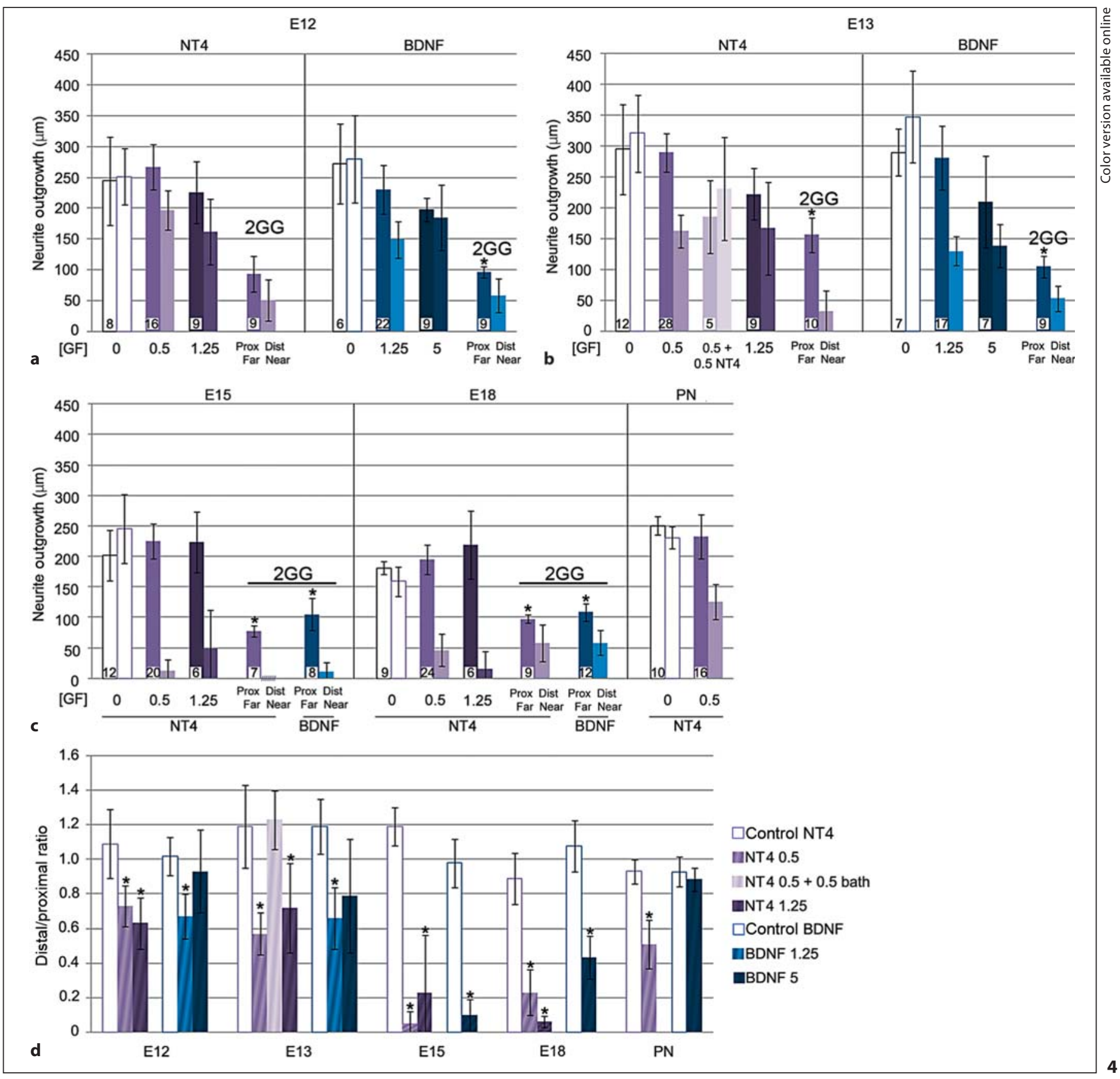


At E15, 20 of 30 ganglion pairs failed to meet the criterion when NT4 beads were used owing to an absence of neurite outgrowth from the distant ganglion. For those ganglion pairs that met the criterion, proximal outgrowth from the distant ganglion was significantly longer than distal outgrowth of the closer ganglion (fig. 3c, 4c). For BDNF beads, only 1 of 13 pairs did not meet the criterion owing to lack of outgrowth from the distant ganglion. With BDNF beads, as with NT4 beads, proximal outgrowth was significantly longer than distal outgrowth for the ganglion pairs that met the criterion (fig. 3d, 4c). At E18, NT4 beads and BDNF beads exerted a predominantly tropic influence on geniculate neurite outgrowth (fig. 4c).

The 2-ganglion experiments show that NT4 and BDNF are both tropic for embryonic geniculate neurites. They also suggest that BDNF is more effective, at least in this assay, perhaps owing to the wider range of concentrations that promote growth.

\section{Discussion}

Our data show that NT4 is similar to BDNF in promoting and attracting geniculate neurites at intermediate concentrations, and suppressing neurite outgrowth at high concentrations, but NT4 is 20 - to 100 -fold more potent than BDNF. This study extends the dose-response and chemoattraction analysis of geniculate neurite outgrowth to initial nerve development stages, revealing dramatic shifts in the efficacy of neurotrophins in promoting, attracting, and suppressing geniculate neurites. Despite differences in the potency of NT4 and BDNF, p75 is necessary for optimum outgrowth by both neurotrophins, but optimal p75 activity is not required for outgrowth suppression. The different potencies combined with the potential to suppress neurite outgrowth explain previously reported differences in the properties of neurites induced by NT4 versus BDNF [10, 23, 24], and provide an explanation for the dramatic difference in taste nerve development observed in mice that overexpress NT4 or BDNF in the lingual epithelium [22]. The recent discovery that $N t f 4 / 5$ mRNA and $B d n f$ mRNA are differentially expressed in the lingual mesenchyme and lingual epithelium when axons arrive in the tongue [15] raises the possibility of concentration-dependent roles in regulating axon growth in vivo.

At all stages examined, the optimum outgrowth was observed at concentrations between 0.25 and $1 \mathrm{ng} / \mathrm{ml}$ for NT4 and $\sim 25 \mathrm{ng} / \mathrm{ml}$ for BDNF, but optimum outgrowth decreased by $\sim$ half between E13 and E15. To determine if p75 was necessary for neurite outgrowth or relevant to differences in the potency of NT4 and BDNF, we used anti-p75 serum. The p75 receptor has been shown to promote TrkB signaling by preventing degradation or enhancing endocytosis and retrograde transport of TrkB [38]. Although we did not determine the level of blockade of p75, it was adequate to reduce neurite outgrowth. Because p75 is the 'low affinity' receptor and has similar affinity for all the neurotrophins, we did not expect blocking it to have a similar effect on outgrowth promoted by $0.5-1 \mathrm{ng} / \mathrm{ml} \mathrm{NT4}$ and outgrowth promoted by $25 \mathrm{ng} / \mathrm{ml}$ BDNF. This finding is particularly surprising in light of the finding that p75 decreases the affinity of NT4, but not BDNF, for TrkB [39]. Note, however, that mutant isoforms of NT4 and BDNF that are impaired in p75 binding have a more dramatic effect on NT4 signaling [40].

High doses of NT4 $(10 \mathrm{ng} / \mathrm{ml})$ or BDNF $(200 \mathrm{ng} / \mathrm{ml})$ strongly suppressed neurite outgrowth from E13 through E18. The greater potency of NT4 in suppressing outgrowth may account for the different morphologies observed in earlier work in which 5-50 ng/ml NT4 or BDNF was used to promote outgrowth from embryonic geniculate ganglia $[10,24]$, because this concentration range would be suppressive for NT4 cultures and optimal for BDNF cultures. Although BDNF and NT4 have been suggested to suppress the outgrowth of neurites supported by NGF or NT3 [41-43], this is the first report (to our knowledge) showing that BDNF and NT4 can suppress outgrowth from neurites that are not supported by other neurotrophins. Suppression of outgrowth supported by other neurotrophins depended on p75, and p75 was also required for suppression of NGF-supported neurons by high levels of NGF [44]. We found that reducing p75 activity did not reduce suppression of geniculate neurite outgrowth by NT4 or BDNF. It did, however, significantly reduce the limited outgrowth observed in $200 \mathrm{ng} / \mathrm{ml}$ BDNF-treated E15 ganglia, indicating that anti-p75 reduced p75 signaling even in the presence of high levels of a neurotrophin. Neurotrophin concentrations that suppressed outgrowth did not do so by increasing cell death in the explants; to the contrary, cell death was significantly less in these ganglia than in explants treated with outgrowth-optimizing concentrations of NT4 or BDNF. Receptor desensitization was proposed to explain the repellent influence of NT3 and NGF on sensory neurites grown at stages corresponding to $\sim$ E15 in rat [44-46], and BDNF administration has been shown to decrease TrkB levels in hippocampal neurons in vivo [47] and in slice cultures [48]. Two observations argue against desensitization explaining the suppression. (1) We observe 
neurites coursing within ganglion explants. (2) We and others do not observe suppression of outgrowth when ganglia are grown on the surface of a substratum (laminin/polylysine coverglasses [our unpubl. obs.]; basement membrane extract [49]). High concentrations of neurotrophic factors may disrupt neurite extension by altering second messenger levels in growth cones [50], altering the expression of receptors for extracellular matrix or cell adhesion molecules [51], or impairing growth through 3-dimensional matrices.

Are in vivo conditions comparable to collagen I gels or rather to the situations described above in which elevated NT4 is not suppressive? Our data predict that expressing BDNF or NT4 at a concentration that is in the optimal range for BDNF would result in suppression of axon growth by NT4. Consistent with this prediction, overexpressing BDNF in the lingual epithelium using the keratin 14 promoter enhanced chorda tympani axon growth and branching along the lingual epithelium, whereas overexpressing NT4 using the same promoter prevented epithelium contact by chorda tympani afferents [22]. Whether suppression occurs during nerve development in wild type mouse or rats is not clear. In rat, geniculate axons enter the tongue on E13 and spend the next 3 days arborizing near, but not contacting the epithelium [10-12, 24, 52]. Semaphorins [24] and neurotrophins regulate target invasion in a variety of systems. BDNF or NT4 repel sensory axons from skin, although in these cases the axons were from NGF- or NT3-dependent neurons [42, 53-55]. The loss of Ntf4/5 mRNA in dorsal lingual epithelium just prior to invasion of the pretaste bud epithelium is consistent with NT4 suppressing growth of taste afferents and preventing premature target contact [15]. Note, however, that overexpression of NT4 in mouse lingual epithelium slows initial innervation of the tongue at E12.5 [22], implying that wild-type levels of NT4 are not maximally suppressive at this stage. Whether the chorda tympani axons extend beyond their wild-type positions in Ntf4/5-/- mice at E12.5 has not been evaluated. Thus, NT4 may be present at a concentration that supports axon extension or that partially suppresses it. A third possibility is that the combination of uniform NT4 and placodal BDNF allows BDNF to attract axons to the vicinity of the placode but results in levels of BDNF and NT4 at the epithelium that, together, are sufficient to stunt the growth of afferents, preventing premature contact. NT4 could also contribute indirectly to the prevention of premature epithelium contact by potentiating the repulsion of geniculate neurites by epithelial Sema3A or Sema3F [10, 24].
Our initial studies suggested that gradients of NT4 emanating from slow-release beads did not bias neurite outgrowth [23]. We now report that beads soaked in one tenth the concentration of NT4 that we had originally used did bias outgrowth from geniculate ganglion explants similarly to gradients of BDNF. The level of bias induced by the gradient of NT4 or BDNF was stage-dependent; being most robust at E15 (targeting) and E18 (target penetration). The extreme bias observed at E15 is unlikely to be explained by trophic activity alone because trophic activity would promote outgrowth proportional to the concentration of the neurotrophin around the perimeter of the explant, but virtually no distal outgrowth was seen at E15. To assess whether the neurotrophins exert a tropic effect directly, we used a 2-ganglion assay [37] in which pairs of ganglia were plated in series adjacent to an NT4- or BDNF-soaked bead. By comparing proximal outgrowth from the distant ganglion and distal outgrowth from the closer ganglion we can distinguish between a trophic influence (proximal growth from the distant ganglion equals distal growth from the closer ganglion) and a tropic influence (proximal outgrowth from the distal ganglion is longer). We previously used a similar assay in which the distant ganglion was positioned on the opposite side of the bead from the closer ganglion [21], assuming that distance from the bead was the sole determinant of neurotrophin concentration. This eliminated the problem of distal outgrowth intermingling with proximal outgrowth. However, the neurotrophin concentration on the distal side of the closer ganglion may be less than the neurotrophin concentration on the opposite side of the bead at the same distance because the ganglion may act as a sink or a barrier to diffusion of the neurotrophin. In light of this concern, we tested NT4 beads as well as BDNF beads at all embryonic stages using the 2-ganglia-in-series arrangement.

The 2-ganglion assays revealed that NT4 and BDNF exert a tropic influence throughout embryonic development, and that the effect is strongest during targeting. This increase in tropic capability correlates with a decrease in the efficacy and potency of NT4 and BDNF in stimulating neurite growth. Perhaps the less exuberant response to neurotrophins underlies the enhanced tropic effects at targeting stages. NT4 does not appear to act as an attractant in vivo, but BDNF does (see 'Introduction'). An advantage of BDNF as an attractant over NT4 is that its lower potency permits a greater range of effective tropic concentrations - whereas NT4 would have to be maintained between 0.25 and $\sim 2.5 \mathrm{ng} / \mathrm{ml}$, BDNF could be attractive between 10 and $100 \mathrm{ng} / \mathrm{ml}$. Our finding that only

Dev Neurosci 2012;34:389-401 
a minority of 2-ganglion studies with NT4 beads could be used in the analysis at E15 underscores the difficulty of using a highly potent chemoattractant in a complex setting, one in which the terrain over which the attractant must act varies in its impact on diffusion of the attractant (e.g. by binding to it).

In summary, NT4 is more potent than BDNF in stimulating and suppressing neurite outgrowth in collagen I gels. Our data predict the results obtained in overexpression studies, validating our in vitro approach. In combination with knockout studies, our work raises the possibility that NT4 has a dual role with regard to nerve devel- opment: promoting the growth of axons in tongue mesenchyme and preventing premature invasion of fungiform placodal epithelium. It will be important to determine if the concentration optima or tropic influences of NT4 and BDNF are altered in the presence of the other factor, and if replacing BDNF with NT4 affects pathfinding to the target and target selection by geniculate axons.

\section{Acknowledgements}

This work was supported by research grants to M.W.R. from the NIDCD, 1R15DC009043-01 and 1R15DC010910-01.

\section{References}

1 Klein R, Lamballe F, Bryant S, Barbacid M: The trkB tyrosine protein kinase is a receptor for neurotrophin-4. Neuron 1992;8:947956.

2 Chao MV: The p75 neurotrophin receptor. J Neurobiol 1994:25:1373-1385.

-3 Conover JC, Erickson JT, Katz DM, Bianchi LM, Poueymirou WT, McClain J, Pan L, Helgren M, Ip NY, Boland P: Neuronal deficits, not involving motor neurons, in mice lacking BDNF and/or NT4. Nature 1995;375: 235-238.

4 Liu X, Ernfors P, Wu H, Jaenisch R: Sensory but not motor neuron deficits in mice lacking NT4 and BDNF. Nature 1995;375:238241.

5 Liebl DJ, Tessarollo L, Palko ME, Parada LF: Absence of sensory neurons before target innervation in brain-derived neurotrophic factor-, neurotrophin 3-, and TrkC-deficient embryonic mice. J Neurosci 1997;17:9113-9121.

-6 Ernfors P, Lee KF, Jaenisch R: Mice lacking brain-derived neurotrophic factor develop with sensory deficits. Nature 1994;368:147150.

7 Patel AV, Huang T, Krimm RF: Lingual and palatal gustatory afferents each depend on both BDNF and NT-4, but the dependence is greater for lingual than palatal afferents. J Comp Neurol 2010;518:3290-3301.

8 Ma L, Lopez GF, Krimm RF: Epithelial-derived brain-derived neurotrophic factor is required for gustatory neuron targeting during a critical developmental period. J Neurosci 2009;29:3354-3364.

-9 Nosrat CA, Blomlof J, ElShamy WM, Ernfors $\mathrm{P}$, Olson L: Lingual deficits in BDNF and NT3 mutant mice leading to gustatory and somatosensory disturbances, respectively. Development 1997;124:1333-1342.

-10 Rochlin MW, O’Connor R, Giger RJ, Verhaagen J, Farbman AI: Comparison of neurotrophin and repellent sensitivities of early embryonic geniculate and trigeminal axons. J Comp Neurol 2000;422:579-593.
11 Farbman AI, Mbiene JP: Early development and innervation of taste bud-bearing papillae on the rat tongue. J Comp Neurol 1991; 304:172-186.

12 Mbiene JP, Mistretta CM: Initial innervation of embryonic rat tongue and developing taste papillae: nerves follow distinctive and spatially restricted pathways. Acta Anat 1997; 160:139-158.

13 Mbiene JP: Taste placodes are primary targets of geniculate but not trigeminal sensory axons in mouse developing tongue. J Neurocytol 2004;33:617-629.

14 Nosrat CA: Neurotrophic factors in the tongue: expression patterns, biological activity, relation to innervation and studies of neurotrophin knockout mice. Ann NY Acad Sci 1998;855:28-49.

15 Huang T, Krimm RF: Developmental expression of Bdnf, $\mathrm{Ntf} 4 / 5$, and $\operatorname{TrkB}$ in the mouse peripheral taste system. Dev Dyn 2010;239:2637-2646.

16 Nosrat CA, Ebendal T, Olson L: Differential expression of brain-derived neurotrophic factor and neurotrophin $3 \mathrm{mRNA}$ in lingual papillae and taste buds indicates roles in gustatory and somatosensory innervation. J Comp Neurol 1996;376:587-602.

17 Nosrat CA, Olson L: Brain-derived neurotrophic factor mRNA is expressed in the developing taste bud-bearing tongue papillae of rat. J Comp Neurol 1995;360:698-704.

18 Zhang C, Brandemihl A, Lau D, Lawton A, Oakley B: BDNF is required for the normal development of taste neurons in vivo. Neuroreport 1997;8:1013-1017.

19 Ringstedt T, Ibanez CF, Nosrat CA: Role of brain-derived neurotrophic factor in target invasion in the gustatory system. J Neurosci 1999;19:3507-3518.

20 Krimm RF, Miller KK, Kitzman PH, Davis BM, Albers KM: Epithelial overexpression of BDNF or NT4 disrupts targeting of taste neurons that innervate the anterior tongue. Dev Biol 2001;232:508-521.
21 Hoshino N, Vatterott P, Egwiekhor A, Rochlin MW: Brain-derived neurotrophic factor attracts geniculate ganglion neurites during embryonic targeting. Dev Neurosci 2010;32: 184-196.

22 Lopez GF, Krimm RF: Epithelial overexpression of BDNF and NT4 produces distinct gustatory axon morphologies that disrupt initial targeting. Dev Biol 2006;292:457-468.

23 Rochlin MW, Egwiekhor A, Vatterott P, Spec A: BDNF attracts geniculate neurites, NT4 does not. Soc Neurosci Abst 2006;32:501-515

- 24 Vilbig R, Cosmano J, Giger R, Rochlin MW Distinct roles for Sema3A, Sema3F, and an unidentified trophic factor in controlling the advance of geniculate axons to gustatory lingual epithelium. J Neurocytol 2004;33:591606.

-25 Minichiello L, Casagranda F, Tatche RS, Stucky CL, Postigo A, Lewin GR, Davies AM, Klein R: Point mutation in trkB causes loss of NT4-dependent neurons without major effects on diverse BDNF responses. Neuron 1998;21:335-345.

26 Bosco A, Linden R: BDNF and NT-4 differentially modulate neurite outgrowth in developing retinal ganglion cells. J Neurosci Res 1999;57:759-769.

27 Hyman C, Juhasz M, Jackson C, Wright P, Ip NY, Lindsay RM: Overlapping and distinct actions of the neurotrophins BDNF, NT-3, and NT-4/5 on cultured dopaminergic and GABAergic neurons of the ventral mesencephalon. J Neurosci 1994;14:335-347.

28 Fan G, Egles C, Sun Y, Minichiello L, Renger JJ, Klein R, Liu G, Jaenisch R: Knocking the NT4 gene into the BDNF locus rescues BDNF deficient mice and reveals distinct NT4 and BDNF activities. Nat Neurosci 2000;3:350357.

29 Yee CL, Jones KR, Finger TE: Brain-derived neurotrophic factor is present in adult mouse taste cells with synapses. J Comp Neurol 2003;459:15-24. 
-30 Beidler LM, Smallman RL: Renewal of cells within taste buds. J Cell Biol 1965;27:263272.

-31 Montavon P, Hellekant G, Farbman A: Immunohistochemical, electrophysiological, and electron microscopical study of rat fungiform taste buds after regeneration of chorda tympani through the non-gustatory lingual nerve. J Comp Neurol 1996;367:491502.

32 Oakley B: Reformation of taste buds by crossed sensory nerves in the rat's tongue. Acta Physiol Scand 1970;79:88-94.

33 Giordano G, Hong S, Faustman EM, Costa LG: Measurements of cell death in neuronal and glial cells. Methods Mol Biol 2011;758: 171-178.

34 Weskamp G, Reichardt LF: Evidence that biological activity of NGF is mediated through a novel subclass of high affinity receptors. Neuron 1991;6:649-663.

- 35 Kruttgen A, Moller JC, Heymach JV Jr, Shooter EM: Neurotrophins induce release of neurotrophins by the regulated secretory pathway. Proc Natl Acad Sci USA 1998;95: 9614-9619.

36 Mbiene JP, Farbman AI: Evidence for stimulus access to taste cells and nerves during development: an electron microscopic study. Microsc Res Tech 1993;26:94-105.

37 Lumsden AG, Davies AM: Earliest sensory nerve fibres are guided to peripheral targets by attractants other than nerve growth factor. Nature 1983;306:786-788.

38 Reichardt LF: Neurotrophin-regulated signalling pathways. Philos Trans R Soc Lond B Biol Sci 2006;361:1545-1564.

39 Huang EJ, Reichardt LF: Trk receptors: roles in neuronal signal transduction. Annu Rev Biochem 2003;72:609-642.
40 Ryden M, Murray-Rust J, Glass D, Ilag LL, Trupp M, Yancopoulos GD, McDonald NQ, Ibanez CF: Functional analysis of mutant neurotrophins deficient in low-affinity binding reveals a role for p75LNGFR in NT-4 signalling. EMBO J 1995;14:1979-1990.

41 Kohn J, Aloyz RS, Toma JG, Haak-Frendscho M, Miller FD: Functionally antagonistic interactions between the TrkA and p75 neurotrophin receptors regulate sympathetic neuron growth and target innervation. J Neurosci 1999;19:5393-5408.

42 Cahoon-Metzger SM, Wang G, Scott SA: Contribution of BDNF-mediated inhibition in patterning avian skin innervation. Dev Biol 2001;232:246-254.

43 Paves H, Saarma M: Neurotrophins as in vitro growth cone guidance molecules for embryonic sensory neurons. Cell Tissue Res 1997;290:285-297.

- 44 Ozdinler PH, Ulupinar E, Erzurumlu RS. Dose and age-dependent axonal responses of embryonic trigeminal neurons to localized NGF via p75NTR receptor. J Neurobiol 2005; 62:189-206.

45 Griffin CG, Letourneau PC: Rapid retraction of neurites by sensory neurons in response to increased concentrations of nerve growth factor. J Cell Biol 1980;86:156-161.

46 Conti AM, Fischer SJ, Windebank AJ: Inhibition of axonal growth from sensory neurons by excess nerve growth factor. Ann Neurol 1997;42:838-846.

-47 Xu B, Michalski B, Racine RJ, Fahnestock M: The effects of brain-derived neurotrophic factor (BDNF) administration on kindling induction, Trk expression and seizure-related morphological changes. Neuroscience 2004;126:521-531.

48 Ji Y, Lu Y, Yang F, Shen W, Tang TT, Feng L, Duan S, Lu B: Acute and gradual increases in BDNF concentration elicit distinct signaling and functions in neurons. Nat Neurosci 2010;13:302-309.

49 Al-Hadlaq SM, Bradley RM, MacCallum DK, Mistretta CM: Embryonic geniculate ganglion neurons in culture have neurotrophin-specific electrophysiological properties. Neuroscience 2003;118:145-159.
0 Tojima T, Itofusa R, Kamiguchi $\mathrm{H}$ : The nitric oxide-cGMP pathway controls the directional polarity of growth cone guidance via modulating cytosolic $\mathrm{Ca}^{2+}$ signals. J Neurosci 2009;29:7886-7897.

51 Thornton MR, Shawcross SG, Mantovani C, Kingham PJ, Birchall MA, Terenghi G: Neurotrophins 3 and 4 differentially regulate NCAM, L1 and N-cadherin expression during peripheral nerve regeneration. Biotechnol Appl Biochem 2008;49:165-174.

52 Hogg ID, Bryant JW: The development of sensory innervation in the mouth and pharynx of the albino Norway rat (Mus norvegicus albinus). J Comp Neurol 1969;136:33-56.

-53 Fundin BT, Silos-Santiago I, Ernfors P, Fagan AM, Aldskogius H, DeChiara TM, Phillips HS, Barbacid M, Yancopoulos GD, Rice FL: Differential dependency of cutaneous mechanoreceptors on neurotrophins, trk receptors, and P75 LNGFR. Dev Biol 1997;190: 94-116.

54 Rice FL, Albers KM, Davis BM, Silos-Santiago I, Wilkinson GA, LeMaster AM, Ernfors P, Smeyne RJ, Aldskogius H, Phillips HS, Barbacid M, DeChiara TM, Yancopoulos GD, Dunne CE, Fundin BT: Differential dependency of unmyelinated and A delta epidermal and upper dermal innervation on neurotrophins, trk receptors, and p75LNGFR. Dev Biol 1998;198:57-81.

55 LeMaster AM, Krimm RF, Davis BM, Noel T, Forbes ME, Johnson JE, Albers KM: Overexpression of brain-derived neurotrophic factor enhances sensory innervation and selectively increases neuron number. J Neurosci 1999;19:5919-5931.

56 Streiner DL: Maintaining standards: differences between the standard deviation and standard error, and when to use each. Can J Psychiatry 1996;41:498-502. 